Review

\title{
Contribution of Viral Mimics of Cellular Genes to KSHV Infection and Disease
}

\section{Shuhei Sakakibara ${ }^{1,2}$ and Giovanna Tosato ${ }^{3, *}$}

1 Department of Molecular Immunology, Research Institute for Microbial Diseases, Osaka University, Suita, Osaka 565-0871, Japan; E-Mail: sakakibara@ ragtime.biken.osaka-u.ac.jp

2 World Premier International Immunology Frontier Research Center, Osaka University, Suita, Osaka 565-0871, Japan

3 Laboratory of Cellular Oncology, National Cancer Institute, National Institutes of Health, Bethesda, MD 20982, USA

* Author to whom correspondence should be addressed; E-Mail: tosatog@ mail.nih.gov; Tel.: +1-301-594-9596; Fax: +1-301-594-9585.

Received: 11 August 2014; in revised form: 5 September 2014 / Accepted: 11 September 2014 / Published: 19 September 2014

\begin{abstract}
Kaposi's sarcoma-associated herpesvirus (KSHV, also named Human herpesvirus $8 \mathrm{HHV}-8)$ is the cause of Kaposi sarcoma (KS), the most common malignancy in HIV-infected individuals worldwide, primary effusion lymphoma (PEL) and multicentric Castleman disease (MCD). KSHV is a double-stranded DNA virus that encodes several homologues of cellular proteins. The structural similarity between viral and host proteins explains why some viral homologues function as their host counterparts, but sometimes at unusual anatomical sites and inappropriate times. In other cases, structural modification in the viral proteins can suppress or override the function of the host homologue, contributing to KSHV-related diseases. For example, viral IL-6 (vIL-6) is sufficiently different from human IL-6 to activate gp130 signaling independent of the $\alpha$ subunit. As a consequence, vIL-6 can activate many cell types that are unresponsive to cellular IL-6, contributing to MCD disease manifestations. Here, we discuss the molecular biology of KSHV homologues of cellular products as conduits of virus/host interaction with a focus on identifying new strategies for therapy of KS and other KSHV-related diseases.
\end{abstract}

Keywords: KSHV; vIL-6; vFLIP; NF-кB; Kaposi sarcoma; primary effusion lymphoma; multicentric Castleman disease; inflammation; tumor angiogenesis 


\section{Introduction}

Kaposi's sarcoma-associated herpesvirus (KSHV) was identified in 1994 as a novel human herpesvirus that was shown to be the cause of Kaposi sarcoma (KS) [1]. Soon thereafter, HIV/AIDSassociated primary effusion lymphoma (PEL) and multicentric Castleman's disease (MCD) were linked to KSHV infection [2-5]. More recently, KICS (KSHV inflammatory cytokine syndrome) was described in HIV-infected patients [6]. All or some of these diseases can co-exist in individual AIDS patients. It is now recognized that while KSHV infection is necessary, it is not sufficient for development of these malignancies. For example, the epidemiology of KSHV shows that the frequency of KSHV infection worldwide is much higher that the frequency of KS, PEL, MCD and KICS [7,8]. KSHV cannot immortalize or transform primary cells of any lineage. In KS, the KSHV-infected "spindle" cells represent a minority of cells within KS lesions within a heterogeneous mixture of other cells, including endothelial cells and inflammatory cells. These other cell components appear critical for the development and progression of KS $[9,10]$.

The disclosure of the entire DNA sequence of KSHV prompted investigation on several viral gene homologues of cellular genes, presumably pirated by the virus during evolution [11]. Since their discovery, many studies have focused on the identification of the roles of the KSHV-pirated genes in the development of KSHV-associated diseases. In this review, we discuss biochemical and functional features of these KSHV genes and gene products, and how we can use this knowledge to target viral gene products that play multiple roles in the viral life cycle, host cell transformation and tumorigenesis.

\section{KSHV-related diseases: KS, MCD, KICS and PEL}

\section{1. $K S$}

The Hungarian dermatologist Moritz Kaposi first described KS in the 1970s, before HIV and KSHV were discovered. Since the worldwide spread of HIV/AIDS, KS has been recognized as one of the AIDS-related diseases. Several epidemiologic types of KS are recognized; these include classic KS (usually arising in elderly men in regions surrounding the Mediterranean Sea), endemic KS (arising in HIV-negative individuals from Africa prior to the AIDS epidemic), epidemic KS (in HIV-infected individuals) and post-transplant KS (in transplant recipients). All these KS types are the same disease.

KS is a multi-focal endothelial tumor with a considerable inflammatory component and vascular proliferation. The multi-focal nature of KS is not due to metastatic spread from a primary tumor but rather has been attributed to blood colonization of independently infected circulating endothelial cells/endothelial precursors [12-14] or opportunistic spread of KSHV [15]. The KSHV-infected tumor cells, the "KS cells" are generally not clonal and represent a minority of cells within KS lesions. Endothelial cells are almost certainly the cells of origin of KS cells [16], but their phenotype and spindle cell morphology indicates that they are not comparable to the normal endothelium. KSHV infection of vascular endothelial cells causes the spindle cell morphology, which is attributable to expression of the KSHV-vFLIP (ORF K13) protein [17-19]. The KSHV-infected KS cells express the lymphatic endothelial cell markers VEGFR3, LYVE-1, VEGF-C, and Prox1, attributable to expression of KSHV-vIL-6 protein [20-22]. KSHV also induces endothelial-mesenchymal transition (EnMT) characterized by reduced expression of the endothelial cell markers CD31, VE-cadherin, CD34 and 
Tie2, and expression of the mesenchymal markers $\alpha$ SMA (Acta2), NG-2 and PDGFR $\beta$ associated with increased cell motility $[23,24]$. This KSHV-induced transdifferentiation of endothelial cells is associated with activation of canonical Notch signaling (Figure 1), which provides a growth advantage to the KSHV-infected endothelial cells and is initiated by vFLIP (ORF K13) and vGPCR (ORF74) via incompletely defined pathways [23-25].

\subsection{MCD and KICS}

Multicentric Castleman disease (MCD) is a systemic lymphoproliferative disorder characterized by intermittent flares of severe inflammatory symptoms that include fever, night sweats, splenomegaly and lymphadenopathy associated with laboratory symptoms of hypoalbuminimia and anemia [26,27]. Characteristically, circulating levels of certain inflammatory cytokines, including IL-6 and IL-10, are elevated. The diagnosis of MCD is based on specific histologic features of the lesions [28]. This includes plasma cell infiltration of the mantle and inter-follicular zones of affected lymph nodes, which generates characteristic concentric layers that resemble the skin layers of onions, and increased vascularization of the interfollicular space.

With the spread of the AIDS epidemic, it was realized that MCD occurs at a higher rate in patients with HIV/AIDS and that in these patients MCD is almost universally associated with KSHV infection [4,5,29]. KSHV-LANA (latency-associated nuclear antigen)-expressing B cells, which are scattered towards the periphery of the affected follicle, are generally monotypic IgM/Ig $\lambda$-expressing B cells $[6,30]$. vIL-6 is often detected in the circulation [6,31], particularly during disease flares, and circulating KSHV is usually present at high levels [26,32]. Recently, an MCD-related syndrome was identified and named KICS (KSHV Inflammatory Cytokine Syndrome): the clinical symptoms of KICS are indistinguishable from those in MCD, but enlarged lymph nodes are not observed and the histologic diagnosis of MCD is missing. Levels of IL-6, vIL-6 and IL-10, and KSHV viral load are comparably high in KICS and HIV-associated KSHV-MCD, and much higher than observed in KS [6,27].

KSHV gene products detected in MCD lesions include vIL-6 (ORF K2), PF-8 (ORF59), LANA (ORF73) and the VIRFs (ORFs K9, K10/10.1, K10.5, K11 and K11.1), indicating that KSHV may be in its lytic phase, in at least a proportion of the infected cells [6,27,33-35].

There is no standard therapy for MCD. Siltuximab, a chimeric neutralizing monoclonal antibody against IL-6 has recently received FDA approval for use in HIV-negative and KSHV-negative MCD. Tocilizumab, a humanized neutralizing antibody against the IL-6R is approved in Japan as a therapy for KSHV-positive and KSHV-negative MCD. Several studies have shown that IL-6/IL-6R targeting (Figure 1) reduces MCD-associated lymph node swelling and fatigue [36,37]. Clinical benefit from the successful targeting of IL-6 or its receptor IL-6R in patients with MCD supports a contributing role of this cytokine in disease pathogenesis and symptomatogy. vIL-6, which is often measurable during MCD flares, is not usually neutralized by IL-6-neutralizing antibodies due to epitope differences [33]. Nonetheless, recent pre-clinical studies have shown that vIL-6 requires some level of IL-6/IL-6R signaling for activity, suggesting that IL-6/IL-6R targeting may also serve to reduce vIL-6 activity [38]. Yet targeting vIL-6 could be a treatment worth investigation in MCD when other treatments are ineffective. Rituximab, a humanized monoclonal antibody against the B-cell marker CD20 has shown efficacy in some cases of MCD (Figure 1) [39]. 


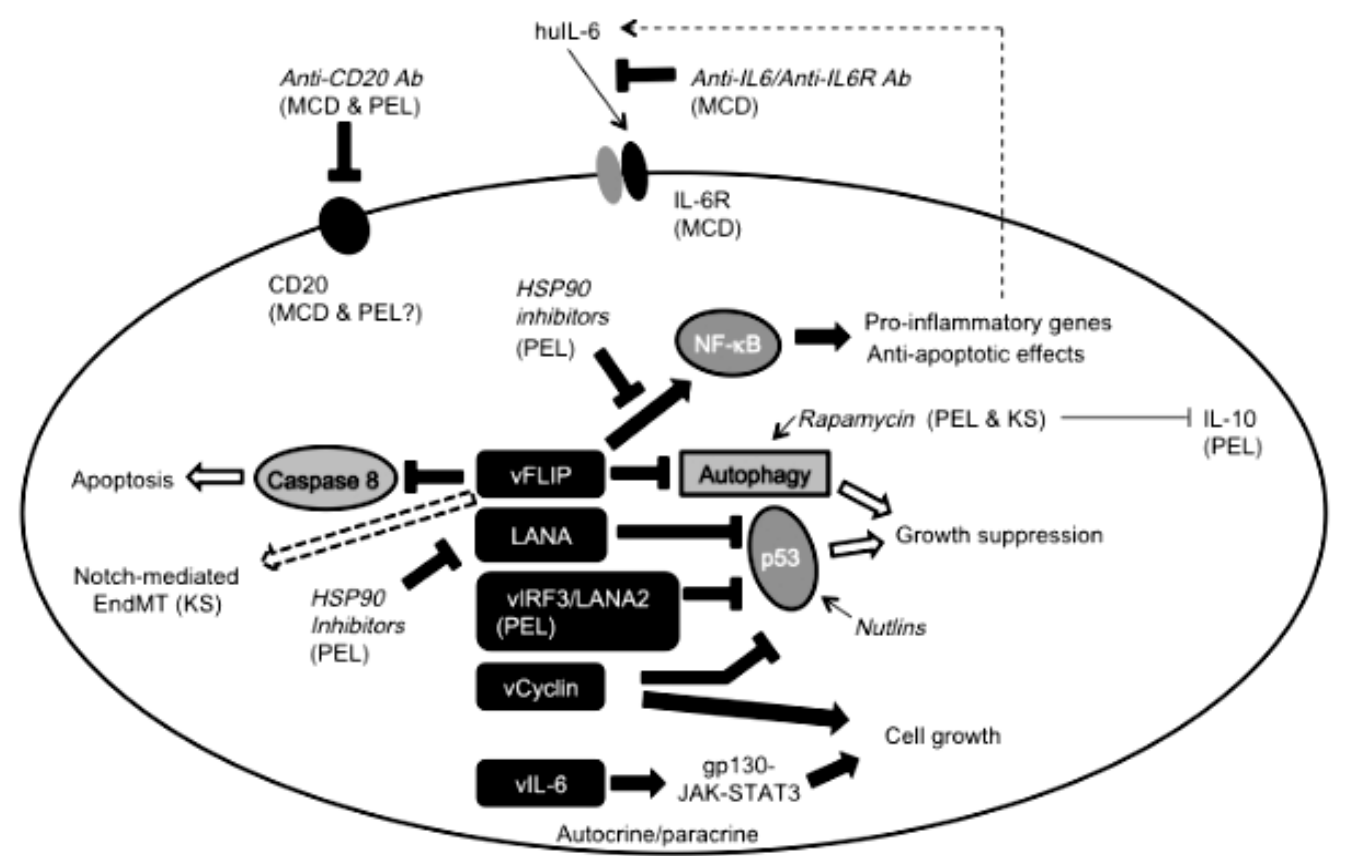

Figure 1. KSHV gene products and potential viral targets for the treatment of KSHV diseases. vFLIP induces pro-inflammatory genes and inhibits cell death by apoptosis and autophagy. vFLIP also enhances Notch-mediated EndMT. Several viral factors, including LANA, vIRF3/LANA2 and vCyclin inhibit p53 function and promote cell cycle progression. Autocrine/paracrine vIL-6 activates STAT3 via gp130. HSP90 inhibitors can target vFLIP and LANA, and could be effective in PEL. Rapamycin induces autophagy and inhibits vIL-10 secretion in PEL cells. Nutlins are p53 activators that could override p53 inhibition induced by several KSHV gene products. Anti-CD20 antibody has shown efficacy in some patients with MCD and PEL. Anti-IL-6R and anti-IL-6 antibodies have shown efficacy in the treatment of MCD.

\subsection{PEL}

PEL is a rare and aggressive non-Hodgkin's lymphoma that typically presents as a liquid malignancy in the body cavities of patients with HIV-AIDS [40]. PEL cells are always infected with KSHV and often are co-infected with EBV [2,40]. Although PEL cells are of B-cell lineage as they display immunoglobulin gene rearrangement, they express the surface markers CD45, CD38, CD71 and CD30, but lack expression of CD20, CD19, surface immunoglobulin, CD79a and other typical B cell surface markers. Despite the absence of surface CD20, there is evidence that rituximab (anti-CD20 antibody) can be an effective treatment for some patients with PEL (Figure 1) [41,42]. Morphologically, PEL cells appear plasmablastic, immunoblastic or anaplastic lymphoid cells.

KSHV does not immortalize B-lymphocytes in culture and success in adaptation of primary PEL cells to culture has been limited. However, a few PEL cell lines have been established from PEL patients, which have been critical to KSHV research as they maintain KSHV infection through passage in culture. KSHV is necessary for the survival of established PEL cell lines [43-45]. In PEL cells KSHV is maintained as an oligoclonal or monoclonal episome, and is mostly latent although a small proportion of cells can spontaneously undergo lytic replication associated with vIL-6 expression [46,47]. 
Viral replication can be induced experimentally in PEL cells with TPA treatment [48]. A characteristic feature of PEL is high level VEGF secretion; VEGF is critical to increased vascular permeability and production of body cavity effusions that is typical of PEL disease, and through these functions contributes to PEL disease progression [49,50]. Cytogenetic characterization of PEL cells has failed to detect common chromosomal aberrations, but $M y c$ is generally amplified [40]. KSHV LANA, which maintains the viral genome during cell division, functionally inhibits the tumor-suppressor genes p53 and Rb [51].

\section{KSHV-pirated Inflammatory Genes: vIL-6, vFLIP and vMIPs}

vIL-6 (ORF K2) is expressed in MCD lesions and in PEL cells in conjunction with LANA (ORF73) and other KSHV genes, including PF-8 (ORF59) and vIRFs (ORFS K9, K10/10.1, K10.5, K11 and K11.1) [6,27,33-35]. Patients with MCD and KICS have detectable vIL-6 in the circulation, and flares of MCD are associated with spikes in circulating levels of vIL-6 [6,31].

The amino acid sequence of vIL-6 exhibits approximately $25 \%$ of similarity to that of human IL-6 [48,52]. Consistent with this modest amino acid conservation, signaling by cellular and vIL-6 differ. Cellular IL-6 requires binding to the non-signaling IL-6R prior to engagement of the signaling chain gp130 [53]. Instead, vIL-6 directly ligates and activates gp130 signaling without a requirement for IL-6R binding [33,54]. Since the distribution of gp130 is much wider than that of IL-6R, it follows that vIL-6 may affect a wider range of cells than its cellular counterpart, which requires the alpha subunit of the receptor, IL-6R. vIL-6 is inefficiently secreted. Nonetheless, vIL-6 can also signal from the intracellular compartment through direct binding to intracellular gp130 [55,56].

An early study reported that subcutaneous inoculation of vIL-6-expressing fibroblasts in nude mice resulted in accelerated fibroblast growth and formation of tumors that were much larger and more vascularized than observed in controls injected with control fibroblasts; tissue levels of VEGF were much higher than in controls [50]. vIL-6 may play a similar growth-promoting, permeabilityenhancing and pro-angiogenic role in KSHV-MCD, KICS and PEL, conditions in which vIL-6 is detected in the circulation [6]. The potential importance of vIL-6 in MCD is confirmed by studies of vIL-6 transgenic mice: H2K promoter-driven vIL-6 expression in hematopoietic cells caused high mortality in most of the founder mice; in the surviving mouse lines, splenomegaly, lymph node enlargement and other manifestations typical of MCD were observed [38].

\section{1. vFLIP}

KSHV-infected cells in KS lesions, the "KS cells" show a characteristic spindle cell shape. KS cells express latency-related genes, including LANA, vFLIP (ORF 71) [viral Fas-associated death domain (FADD) interleukin-1 $\beta$-converting enzyme (FLICE) inhibitory protein] and kaposin (ORF K12), and lytic genes, including vGPCR (ORF 74) and vCyclin (ORF72) [57]. Intriguingly, KSHV vFLIP alone is sufficient to change the typical cobblestone morphology of endothelial cells into that of elongated, spindle-like cells [17-19]. vFLIP was originally identified as a viral homologue of cFLIP (cellular FLICE-like inhibitory protein), which inhibits Caspase 8 activity induced by death domain-containing receptors [58]. vFLIP activates the canonical NF- $\kappa \mathrm{B}$ pathway (Figure 1), and the morphologic change into spindle-cells induced by vFLIP is dependent upon vFLIP activation of the NF- $\kappa \mathrm{B}$ pathway. Constitutive NF- $\kappa \mathrm{B}$ activation leads to transcriptional regulation of NF- $\kappa \mathrm{B}$ target genes, including 
increased expression of proinflammatory cytokines (GM-CSF, IL-6 and $I L-1 \beta)$, chemokines (Mipl $\alpha$, Rantes, $M c p-2, I p-10$ and $I$-tac) and interferon-responsive genes, which are likely critical contributors to the prominent proinflammatory phenotype of KS [19,57]. Furthermore, persistent endothelial NF- $\kappa$ B activation by vFLIP induces expression of the NF- $\kappa$ B regulator A20/TNFAIP3, which represses vFLIP-induced NF- $\kappa \mathrm{B}$ activation and augments IKK1 protein expression [59]. A20, a ubiquitin-editing enzyme, inhibits NF- $\mathrm{BB}$ activation by $\mathrm{TNF} \alpha$ and vFLIP, albeit through distinct mechanisms [59]. When $\mathrm{TNF} \alpha$ induces NF- $\mathrm{BB}$ activation, A20 ubiquitinates IKK $\gamma$ promoting proteasome-dependent degradation and reducing downstream signaling [60]. Instead, when vFLIP-induces NF- $\kappa$ B activation, the de-ubiquitination activity of A20 is dispensable for NF- $\kappa \mathrm{B}$ inhibition [59]. High-level expression of A20 in vFLIP-expressing cells and tissues suggests an important role of the NF- $\kappa$ B pathway in KS [59].

Another function of vFLIP is regulation of cell death by autophagy, a tightly regulated process of cell degradation leading to the removal of cytoplasmic cell components [61]. vFLIP inhibits autophagy and promotes cell survival. This pro-survival function is mediated by vFLIP binding to Atg3, preventing Atg3 binding to the ubiquitin-like protein LC3, which is critical for autophagosome biogenesis [61]. Rapamycin, an mTOR inhibitor with anti-tumor activity, is a potent inducer of autophagy. Despite vFLIP inhibiting Rapamycin-induced autophagy [61], Rapamycin stops growth and KSHV reactivation in PEL cells, which express vFLIP (Figure 1) [62-64]. In addition, Rapamycin reduces PEL and KS tumor progression in mice [63,65]. The anti-PEL activity has been attributed to Rapamycin inhibiting secretion of IL-10, an essential autocrine growth factor for PEL $[62,63]$.

\section{2. vMIPs}

KSHV encodes the proteins vMIP-I (ORF K6), vMIP-II (ORF K4) that share extensive sequence identity (43\% and $52 \%$, respectively) to the cellular cytokine MIP1 $\alpha$ (macrophage inflammatory protein/CCL3), and vMIPIII (ORF K4.1), which is more distantly related to MIP1 $\alpha$ [66,67]. vMIP-1 binds to the CCR8 receptor, resulting in $\mathrm{Ca}^{2+}$ ion-dependent signaling [68]. vMIP-2 was shown to bind to CCR3 and CCR8 acting as an agonist and to also bind to a variety of other chemokine receptors acting as a broad spectrum antagonist [68-71]. vMIP-III preferentially binds and activates CCR4, acting as a chemoattractant for Th2-type memory $\mathrm{T}$ cells, which express this receptor in the skin $[67,72]$. The cutaneous location of KS has suggested an important role of vMIP-III as an attractant of pro-tumorigenic Th2-type cells that would favor KS progression rather than Th1-type cells, which usually exert anti-tumor activity [67]. Importantly, all three vMIPs were shown to exert pro-angiogenic activity in model systems, and it was proposed that they contribute to the pro-angiogenic phenotype of KS and MCD [67,70]. vMIPs are expressed in the lytic phase of KSHV infection, and have been detected in KS and MCD, which contain spontaneously reactivated cells: vMIP-I and vMIP-II were detected in tissues affected with MCD, whereas only vMIP-II was detected in KS tissues [73].

Currently, there are no preclinical models to assess vMIPs function in vivo, and the complexities of chemokine receptor/ligand interactions and redundancy of viral and cellular chemokines suggests that specific targeting these viral products may be difficult. An intriguing approach to overcome some of the complexities of the chemokine system has focused on the development of a therapeutic neutralizing antibody that inactivates multiple chemokines [74]. 


\section{The NF-kB and p53 Pathways: Common Targets of KSHV Gene Products Relevant to KSHV Malignancies}

Non-Hodgkin's lymphomas generally display constitutive activation of NF- $\kappa \mathrm{B}$ due to defects in its homeostatic control [75]. KSHV constitutively activates NF- $\kappa B$ via physical interaction of vFLIP with IKK $\gamma /$ NEMO within the I- $\mathrm{B}$ kinase (IKK) complex (Figure 1) [76,77]. The molecular chaperone HSP90 binds to the vFLIP/IKK complex in PEL cells (Figure 1) [78]. Consistent with an essential function of NF- $\kappa \mathrm{B}$ activity in sustaining PEL cell survival, inhibition of NF- $\kappa \mathrm{B}$ results in PEL cell death $[79,80]$. In addition, inhibition of HSP90 or vFLIP kills KSHV-infected PEL cell lines, inducing apoptosis and autophagy $[44,78,81,82]$. The function of HSP90 is to maintain or promote the proper conformation of other "client" proteins, which include many oncogenes and KSHV LANA [83-85]. Inhibition of HSP90 causes "client" proteins to acquire abnormal conformation leading to their ubiquitination and proteasome degradation [84]. Thus, HSP90 inhibitors (Figure 1) are being developed as potential therapeutics in cancer, and some drugs have reached clinical testing in different cancer types, but not in PEL or other KSHV-related malignancies [86,87]. Since HSP90 regulates the stability of several IKK kinases and disruption of HSP90 blocks NF- $\kappa B$ activation [88,89], HSP90 inhibitors hold promise in the treatment of PEL.

Other than vIL-6 and vFLIP, there are several viral inflammatory factors encoded by the KSHV genome [48]. vIRF1 (ORF K9), which aligns in the middle of viral genome [11], inhibits type-I IFN signaling and expression of genes under IFN regulatory control [90]. vIRF3/LANA2, which is expressed in PEL but not in KS tissues, inhibits p53 transcriptional activity and pro-apoptotic function (Figure 1) [91]. An important non-inflammatory viral homologue of a cellular protein is vCyclin, which can overcome retinoblastoma (RB) tumor suppressor protein-mediated cell cycle arrest [92], and inhibit p53 expression and function [93]. Transgenic expression of vCyclin in mice under the control of VEGFR3, alters lymphatic vessel structure and causes lymphatic vessel dysfunction [94]. Other than viral homologues, LANA, which is expressed in all KHSV-infected cells, also interacts with p53 and inhibits its transcriptional activity (Figure 1) [51]. The oncoprotein MDM2 (Monocyte to Macrophage Differentiation Factor-2) binds to p53 and negatively regulates its stability and pro-apoptotic activity [95]. Thus, inhibitors of MDM2 would be expected to activate p53 and increase cell death, which would be a valuable approach to reducing tumor cell growth. Nutlins are selective inhibitors of the p53-MDM2 interaction, which cause p53-dependent apoptosis in cancer cells (Figure 1) [96]. Nutlin-3a, a small molecule inhibitor of the p53/MDM2 interaction, which promotes p53 reactivation, kills PEL cells in culture and has potent anti-tumor activity in mice bearing PEL tumors [97,98].

\section{Future Directions}

We have described KSHV-pirated genes and their functions in KSHV-related diseases. It is clear that viral homologues of cellular genes that have been captured during virus-host co-evolution play important roles in KSHV life cycle and pathogenicity. Therefore, a clear understanding of the function of these factors can provide precise therapeutic targets directed at the pathogen. Precision medicine is a current goal in cancer therapy, as it ideally targets important unique tumor targets while sparing the normal cell counterparts. Targeting KSHV-specific factors is in line with current efforts. 


\section{Acknowledgments}

This work is supported by the intramural research program of CCR/NCI/NIH. We thank R. Yarchoan, T. Uldrick and M. Polizzotto for helpful discussions.

\section{Author Contributions}

S.S. and G.T. wrote this paper.

\section{Conflicts of Interest}

The authors declare no conflict of interest.

\section{References and Notes}

1. Chang, Y.; Cesarman, E.; Pessin, M.S.; Lee, F.; Culpepper, J.; Knowles, D.M.; Moore, P.S. Identification of herpesvirus-like DNA sequences in AIDS-associated Kaposi's sarcoma. Science 1994, 266, 1865-1869.

2. Cesarman, E.; Chang, Y.; Moore, P.S.; Said, J.W.; Knowles, D.M. Kaposi's sarcoma-associated herpesvirus-like DNA sequences in AIDS-related body-cavity-based lymphomas. N. Engl. J. Med. 1995, 332, 1186-1191.

3. Nador, R.G.; Cesarman, E.; Knowles, D.M.; Said, J.W. Herpes-like DNA sequences in a body-cavity-based lymphoma in an HIV-negative patient. N. Engl. J. Med. 1995, 333, 943.

4. Soulier, J.; Grollet, L.; Oksenhendler, E.; Cacoub, P.; Cazals-Hatem, D.; Babinet, P.; D’Agay, M.F.; Clauvel, J.P.; Raphael, M.; Degos, L.; et al. Kaposi's sarcoma-associated herpesvirus-like DNA sequences in multicentric Castleman's disease. Blood 1995, 86, 1276-1280.

5. Dupin, N.; Diss, T.L.; Kellam, P.; Tulliez, M.; Du, M.Q.; Sicard, D.; Weiss, R.A.; Isaacson, P.G.; Boshoff, C. HHV-8 is associated with a plasmablastic variant of Castleman disease that is linked to HHV-8-positive plasmablastic lymphoma. Blood 2000, 95, 1406-1412.

6. Uldrick, T.S.; Wang, V.; O’Mahony, D.; Aleman, K.; Wyvill, K.M.; Marshall, V.; Steinberg, S.M.; Pittaluga, S.; Maric, I.; Whitby, D.; et al. An interleukin-6-related systemic inflammatory syndrome in patients co-infected with Kaposi sarcoma-associated herpesvirus and HIV but without Multicentric Castleman disease. Clin. Infect. Dis. 2010, 51, 350-358.

7. Martin, J.N.; Ganem, D.E.; Osmond, D.H.; Page-Shafer, K.A.; Macrae, D.; Kedes, D.H. Sexual transmission and the natural history of human herpesvirus 8 infection. N. Engl. J. Med. 1998, 338, 948-954.

8. Dollard, S.C.; Butler, L.M.; Jones, A.M.; Mermin, J.H.; Chidzonga, M.; Chipato, T.; Shiboski, C.H.; Brander, C.; Mosam, A.; Kiepiela, P.; et al. Substantial regional differences in human herpesvirus 8 seroprevalence in sub-Saharan Africa: Insights on the origin of the "Kaposi's sarcoma belt". Int. J. Cancer 2010, 127, 2395-2401.

9. Niedt, G.W.; Prioleau, P.G. Kaposi's sarcoma occurring in a dermatome previously involved by herpes zoster. J. Am. Acad. Dermatol. 1988, 18, 448-451. 
10. Achenbach, C.J.; Harrington, R.D.; Dhanireddy, S.; Crane, H.M.; Casper, C.; Kitahata, M.M. Paradoxical immune reconstitution inflammatory syndrome in $\mathrm{HIV}$-infected patients treated with combination antiretroviral therapy after AIDS-defining opportunistic infection. Clin. Infect. Dis. 2012, 54, 424-433.

11. Russo, J.J.; Bohenzky, R.A.; Chien, M.C.; Chen, J.; Yan, M.; Maddalena, D.; Parry, J.P.; Peruzzi, D.; Edelman, I.S.; Chang, Y.; et al. Nucleotide sequence of the Kaposi sarcoma-associated herpesvirus (HHV8). Proc. Natl. Acad. Sci. USA 1996, 93, 14862-14867.

12. Browning, P.J.; Sechler, J.M.; Kaplan, M.; Washington, R.H.; Gendelman, R.; Yarchoan, R.; Ensoli, B.; Gallo, R.C. Identification and culture of Kaposi's sarcoma-like spindle cells from the peripheral blood of human immunodeficiency virus-1-infected individuals and normal controls. Blood 1994, 84, 2711-2720.

13. Yao, L.; Salvucci, O.; Cardones, A.R.; Hwang, S.T.; Aoki, Y.; De La Luz Sierra, M.; Sajewicz, A.; Pittaluga, S.; Yarchoan, R.; Tosato, G. Selective expression of stromal-derived factor-1 in the capillary vascular endothelium plays a role in Kaposi sarcoma pathogenesis. Blood 2003, 102, 3900-3905.

14. Della Bella, S.; Taddeo, A.; Calabro, M.L.; Brambilla, L.; Bellinvia, M.; Bergamo, E.; Clerici, M.; Villa, M.L. Peripheral blood endothelial progenitors as potential reservoirs of Kaposi's sarcoma-associated herpesvirus. PLoS One 2008, 3, e1520.

15. Duus, K.M.; Lentchitsky, V.; Wagenaar, T.; Grose, C.; Webster-Cyriaque, J. Wild-type Kaposi's sarcoma-associated herpesvirus isolated from the oropharynx of immune-competent individuals has tropism for cultured oral epithelial cells. J. Virol. 2004, 78, 4074-4084.

16. Carroll, P.A.; Brazeau, E.; Lagunoff, M. Kaposi's sarcoma-associated herpesvirus infection of blood endothelial cells induces lymphatic differentiation. Virology 2004, 328, 7-18.

17. Grossmann, C.; Podgrabinska, S.; Skobe, M.; Ganem, D. Activation of NF-kappaB by the latent vFLIP gene of Kaposi's sarcoma-associated herpesvirus is required for the spindle shape of virus-infected endothelial cells and contributes to their proinflammatory phenotype. J. Virol. 2006, 80, 7179-7185.

18. Matta, H.; Surabhi, R.M.; Zhao, J.; Punj, V.; Sun, Q.; Schamus, S.; Mazzacurati, L.; Chaudhary, P.M. Induction of spindle cell morphology in human vascular endothelial cells by human herpesvirus 8-encoded viral FLICE inhibitory protein K13. Oncogene 2007, 26, 1656-1660.

19. Sakakibara, S.; Pise-Masison, C.A.; Brady, J.N.; Tosato, G. Gene regulation and functional alterations induced by Kaposi's sarcoma-associated herpesvirus-encoded ORFK13/vFLIP in endothelial cells. J. Virol. 2009, 83, 2140-2153.

20. Hong, Y.K.; Foreman, K.; Shin, J.W.; Hirakawa, S.; Curry, C.L.; Sage, D.R.; Libermann, T.; Dezube, B.J.; Fingeroth, J.D.; Detmar, M. Lymphatic reprogramming of blood vascular endothelium by Kaposi sarcoma-associated herpesvirus. Nat. Genet. 2004, 36, 683-685.

21. Boshoff, C.; Whitby, D.; Hatziioannou, T.; Fisher, C.; van der Walt, J.; Hatzakis, A.; Weiss, R.; Schulz, T. Kaposi's-sarcoma-associated herpesvirus in HIV-negative Kaposi's sarcoma. Lancet 1995, 345, 1043-1044.

22. Morris, V.A.; Punjabi, A.S.; Wells, R.C.; Wittkopp, C.J.; Vart, R.; Lagunoff, M. The KSHV viral IL-6 homolog is sufficient to induce blood to lymphatic endothelial cell differentiation. Virology 2012, 428, 112-120. 
23. Cheng, F.; Pekkonen, P.; Laurinavicius, S.; Sugiyama, N.; Henderson, S.; Gunther, T.; Rantanen, V.; Kaivanto, E.; Aavikko, M.; Sarek, G.; et al. KSHV-initiated notch activation leads to membrane-type-1 matrix metalloproteinase-dependent lymphatic endothelial-to-mesenchymal transition. Cell Host Microbe 2011, 10, 577-590.

24. Gasperini, P.; Espigol-Frigole, G.; McCormick, P.J.; Salvucci, O.; Maric, D.; Uldrick, T.S.; Polizzotto, M.N.; Yarchoan, R.; Tosato, G. Kaposi sarcoma herpesvirus promotes endothelial-to-mesenchymal transition through Notch-dependent signaling. Cancer Res. 2012, 72 , 1157-1169.

25. Emuss, V.; Lagos, D.; Pizzey, A.; Gratrix, F.; Henderson, S.R.; Boshoff, C. KSHV manipulates Notch signaling by DLL4 and JAG1 to alter cell cycle genes in lymphatic endothelia. PLoS Pathog. 2009, 5, e1000616.

26. Oksenhendler, E.; Carcelain, G.; Aoki, Y.; Boulanger, E.; Maillard, A.; Clauvel, J.P.; Agbalika, F. High levels of human herpesvirus 8 viral load, human interleukin-6, interleukin-10, and $\mathrm{C}$ reactive protein correlate with exacerbation of multicentric castleman disease in HIV-infected patients. Blood 2000, 96, 2069-2073.

27. Polizzotto, M.N.; Uldrick, T.S.; Hu, D.; Yarchoan, R. Clinical manifestations of kaposi sarcoma herpesvirus lytic activation: Multicentric Castleman Disease (KSHV-MCD) and the KSHV inflammatory cytokine syndrome. Front. Microbiol. 2012, 3, 73.

28. Cronin, D.M.; Warnke, R.A. Castleman disease: An update on classification and the spectrum of associated lesions. Adv. Anat. Pathol. 2009, 16, 236-246.

29. Pluda, J.M.; Yarchoan, R.; Jaffe, E.S.; Feuerstein, I.M.; Solomon, D.; Steinberg, S.M.; Wyvill, K.M.; Raubitschek, A.; Katz, D.; Broder, S. Development of non-Hodgkin lymphoma in a cohort of patients with severe human immunodeficiency virus (HIV) infection on long-term antiretroviral therapy. Ann. Intern. Med. 1990, 113, 276-282.

30. Chadburn, A.; Hyjek, E.M.; Tam, W.; Liu, Y.; Rengifo, T.; Cesarman, E.; Knowles, D.M. Immunophenotypic analysis of the Kaposi sarcoma herpesvirus (KSHV; HHV-8)-infected B cells in HIV+ multicentric Castleman disease (MCD). Histopathology 2008, 53, 513-524.

31. Aoki, Y.; Tosato, G.; Fonville, T.W.; Pittaluga, S. Serum viral interleukin-6 in AIDS-related multicentric Castleman disease. Blood 2001, 97, 2526-2527.

32. Polizzotto, M.N.; Uldrick, T.S.; Wang, V.; Aleman, K.; Wyvill, K.M.; Marshall, V.; Pittaluga, S.; O’Mahony, D.; Whitby, D.; Tosato, G.; et al. Human and viral interleukin-6 and other cytokines in Kaposi sarcoma herpesvirus-associated multicentric Castleman disease. Blood 2013, 122, 4189-4198.

33. Aoki, Y.; Narazaki, M.; Kishimoto, T.; Tosato, G. Receptor engagement by viral interleukin-6 encoded by Kaposi sarcoma-associated herpesvirus. Blood 2001, 98, 3042-3049.

34. Du, M.Q.; Diss, T.C.; Liu, H.; Ye, H.; Hamoudi, R.A.; Cabecadas, J.; Dong, H.Y.; Harris, N.L.; Chan, J.K.; Rees, J.W.; et al. KSHV- and EBV-associated germinotropic lymphoproliferative disorder. Blood 2002, 100, 3415-3418.

35. Katano, H.; Sato, Y.; Kurata, T.; Mori, S.; Sata, T. Expression and localization of human herpesvirus 8-encoded proteins in primary effusion lymphoma, Kaposi's sarcoma, and multicentric Castleman's disease. Virology 2000, 269, 335-344. 
36. Nishimoto, N.; Sasai, M.; Shima, Y.; Nakagawa, M.; Matsumoto, T.; Shirai, T.; Kishimoto, T.; Yoshizaki, K. Improvement in Castleman's disease by humanized anti-interleukin-6 receptor antibody therapy. Blood 2000, 95, 56-61.

37. Nishimoto, N.; Kanakura, Y.; Aozasa, K.; Johkoh, T.; Nakamura, M.; Nakano, S.; Nakano, N.; Ikeda, Y.; Sasaki, T.; Nishioka, K.; et al. Humanized anti-interleukin-6 receptor antibody treatment of multicentric Castleman disease. Blood 2005, 106, 2627-2632.

38. Suthaus, J.; Stuhlmann-Laeisz, C.; Tompkins, V.S.; Rosean, T.R.; Klapper, W.; Tosato, G.; Janz, S.; Scheller, J.; Rose-John, S. HHV-8-encoded viral IL-6 collaborates with mouse IL-6 in the development of multicentric Castleman disease in mice. Blood 2012, 119, 5173-5181.

39. Marcelin, A.G.; Aaron, L.; Mateus, C.; Gyan, E.; Gorin, I.; Viard, J.P.; Calvez, V.; Dupin, N. Rituximab therapy for HIV-associated Castleman disease. Blood 2003, 102, 2786-2788.

40. Knowles, D.M.; Inghirami, G.; Ubriaco, A.; Dalla-Favera, R. Molecular genetic analysis of three AIDS-associated neoplasms of uncertain lineage demonstrates their B-cell derivation and the possible pathogenetic role of the Epstein-Barr virus. Blood 1989, 73, 792-799.

41. Perez, C.L.; Rudoy, S. Anti-CD20 monoclonal antibody treatment of human herpesvirus 8-associated, body cavity-based lymphoma with an unusual phenotype in a human immunodeficiency virus-negative patient. Clin. Diagn. Lab. Immunol. 2001, 8, 993-996.

42. Siddiqi, T.; Joyce, R.M. A case of HIV-negative primary effusion lymphoma treated with bortezomib, pegylated liposomal doxorubicin, and rituximab. Clin. Lymphoma Myeloma 2008, 8 , 300-304.

43. Kliche, S.; Kremmer, E.; Hammerschmidt, W.; Koszinowski, U.; Haas, J. Persistent infection of Epstein-Barr virus-positive B lymphocytes by human herpesvirus 8. J. Virol. 1998, 72, 8143-8149.

44. Guasparri, I.; Keller, S.A.; Cesarman, E. KSHV vFLIP is essential for the survival of infected lymphoma cells. J. Exp. Med. 2004, 199, 993-1003.

45. Godfrey, A.; Anderson, J.; Papanastasiou, A.; Takeuchi, Y.; Boshoff, C. Inhibiting primary effusion lymphoma by lentiviral vectors encoding short hairpin RNA. Blood 2005, 105, 2510-2518.

46. Judde, J.G.; Lacoste, V.; Briere, J.; Kassa-Kelembho, E.; Clyti, E.; Couppie, P.; Buchrieser, C.; Tulliez, M.; Morvan, J.; Gessain, A. Monoclonality or oligoclonality of human herpesvirus 8 terminal repeat sequences in Kaposi's sarcoma and other diseases. J. Natl. Cancer Inst. 2000, 92, 729-736.

47. Speck, S.H.; Ganem, D. Viral latency and its regulation: Lessons from the gamma-herpesviruses. Cell Host Microbe 2010, 8, 100-115.

48. Moore, P.S.; Boshoff, C.; Weiss, R.A.; Chang, Y. Molecular mimicry of human cytokine and cytokine response pathway genes by KSHV. Science 1996, 274, 1739-1744.

49. Aoki, Y.; Tosato, G. Role of vascular endothelial growth factor/vascular permeability factor in the pathogenesis of Kaposi's sarcoma-associated herpesvirus-infected primary effusion lymphomas. Blood 1999, 94, 4247-4254.

50. Aoki, Y.; Jaffe, E.S.; Chang, Y.; Jones, K.; Teruya-Feldstein, J.; Moore, P.S.; Tosato, G. Angiogenesis and hematopoiesis induced by Kaposi's sarcoma-associated herpesvirus-encoded interleukin-6. Blood 1999, 93, 4034-4043. 
51. Radkov, S.A.; Kellam, P.; Boshoff, C. The latent nuclear antigen of Kaposi sarcoma-associated herpesvirus targets the retinoblastoma-E2F pathway and with the oncogene Hras transforms primary rat cells. Nat. Med. 2000, 6, 1121-1127.

52. Nicholas, J.; Ruvolo, V.R.; Burns, W.H.; Sandford, G.; Wan, X.; Ciufo, D.; Hendrickson, S.B.; Guo, H.G.; Hayward, G.S.; Reitz, M.S. Kaposi's sarcoma-associated human herpesvirus-8 encodes homologues of macrophage inflammatory protein-1 and interleukin-6. Nat. Med. 1997, 3, 287-292.

53. Murakami, M.; Hibi, M.; Nakagawa, N.; Nakagawa, T.; Yasukawa, K.; Yamanishi, K.; Taga, T.; Kishimoto, T. IL-6-induced homodimerization of gp130 and associated activation of a tyrosine kinase. Science 1993, 260, 1808-1810.

54. Wan, X.; Wang, H.; Nicholas, J. Human herpesvirus 8 interleukin-6 (vIL-6) signals through gp130 but has structural and receptor-binding properties distinct from those of human IL-6. J. Virol. 1999, 73, 8268-8278.

55. Meads, M.B.; Medveczky, P.G. Kaposi's sarcoma-associated herpesvirus-encoded viral interleukin-6 is secreted and modified differently than human interleukin-6: Evidence for a unique autocrine signaling mechanism. J. Biol. Chem. 2004, 279, 51793-51803.

56. Chen, D.; Sandford, G.; Nicholas, J. Intracellular signaling mechanisms and activities of human herpesvirus 8 interleukin-6. J. Virol. 2009, 83, 722-733.

57. Ganem, D. KSHV infection and the pathogenesis of Kaposi's sarcoma. Annu. Rev. Pathol. 2006, 1, 273-296.

58. Chaudhary, P.M.; Jasmin, A.; Eby, M.T.; Hood, L. Modulation of the NF-kappa B pathway by virally encoded death effector domains-containing proteins. Oncogene 1999, 18, 5738-5746.

59. Sakakibara, S.; Espigol-Frigole, G.; Gasperini, P.; Uldrick, T.S.; Yarchoan, R.; Tosato, G. A20/TNFAIP3 inhibits NF-kappaB activation induced by the Kaposi's sarcoma-associated herpesvirus vFLIP oncoprotein. Oncogene 2013, 32, 1223-1232.

60. Shembade, N.; Ma, A.; Harhaj, E.W. Inhibition of NF-kappaB signaling by A20 through disruption of ubiquitin enzyme complexes. Science 2010, 327, 1135-1139.

61. Lee, J.S.; Li, Q.; Lee, J.Y.; Lee, S.H.; Jeong, J.H.; Lee, H.R.; Chang, H.; Zhou, F.C.; Gao, S.J.; Liang, C.; et al. FLIP-mediated autophagy regulation in cell death control. Nat. Cell Biol. 2009, $11,1355-1362$.

62. Sin, S.H.; Roy, D.; Wang, L.; Staudt, M.R.; Fakhari, F.D.; Patel, D.D.; Henry, D.; Harrington, W.J., Jr.; Damania, B.A.; Dittmer, D.P. Rapamycin is efficacious against primary effusion lymphoma (PEL) cell lines in vivo by inhibiting autocrine signaling. Blood 2007, 109, 2165-2173.

63. Gasperini, P.; Tosato, G. Targeting the mammalian target of Rapamycin to inhibit VEGF and cytokines for the treatment of primary effusion lymphoma. Leukemia 2009, 23, 1867-1874.

64. Nichols, L.A.; Adang, L.A.; Kedes, D.H. Rapamycin blocks production of KSHV/HHV8: Insights into the anti-tumor activity of an immunosuppressant drug. PLoS One 2011, 6, e14535.

65. Roy, D.; Sin, S.H.; Lucas, A.; Venkataramanan, R.; Wang, L.; Eason, A.; Chavakula, V.; Hilton, I.B.; Tamburro, K.M.; Damania, B.; et al. mTOR inhibitors block Kaposi sarcoma growth by inhibiting essential autocrine growth factors and tumor angiogenesis. Cancer Res. 2013, 73, 2235-2246. 
66. Moore, P.S.; Gao, S.J.; Dominguez, G.; Cesarman, E.; Lungu, O.; Knowles, D.M.; Garber, R.; Pellett, P.E.; McGeoch, D.J.; Chang, Y. Primary characterization of a herpesvirus agent associated with Kaposi's sarcomae. J. Virol. 1996, 70, 549-558.

67. Stine, J.T.; Wood, C.; Hill, M.; Epp, A.; Raport, C.J.; Schweickart, V.L.; Endo, Y.; Sasaki, T.; Simmons, G.; Boshoff, C.; et al. KSHV-encoded CC chemokine vMIP-III is a CCR4 agonist, stimulates angiogenesis, and selectively chemoattracts TH2 cells. Blood 2000, 95, 1151-1157.

68. Dairaghi, D.J.; Fan, R.A.; McMaster, B.E.; Hanley, M.R.; Schall, T.J. HHV8-encoded vMIP-I selectively engages chemokine receptor CCR8. Agonist and antagonist profiles of viral chemokines. J. Biol. Chem. 1999, 274, 21569-21574.

69. Kledal, T.N.; Rosenkilde, M.M.; Coulin, F.; Simmons, G.; Johnsen, A.H.; Alouani, S.; Power, C.A.; Luttichau, H.R.; Gerstoft, J.; Clapham, P.R.; et al. A broad-spectrum chemokine antagonist encoded by Kaposi's sarcoma-associated herpesvirus. Science 1997, 277, 1656-1659.

70. Boshoff, C.; Endo, Y.; Collins, P.D.; Takeuchi, Y.; Reeves, J.D.; Schweickart, V.L.; Siani, M.A.; Sasaki, T.; Williams, T.J.; Gray, P.W.; et al. Angiogenic and HIV-inhibitory functions of KSHV-encoded chemokines. Science 1997, 278, 290-294.

71. Sozzani, S.; Luini, W.; Bianchi, G.; Allavena, P.; Wells, T.N.; Napolitano, M.; Bernardini, G.; Vecchi, A.; D’Ambrosio, D.; Mazzeo, D.; et al. The viral chemokine macrophage inflammatory protein-II is a selective Th2 chemoattractant. Blood 1998, 92, 4036-4039.

72. Campbell, J.J.; Haraldsen, G.; Pan, J.; Rottman, J.; Qin, S.; Ponath, P.; Andrew, D.P.; Warnke, R.; Ruffing, N.; Kassam, N.; et al. The chemokine receptor CCR4 in vascular recognition by cutaneous but not intestinal memory T cells. Nature 1999, 400, 776-780.

73. Nakano, K.; Katano, H.; Tadagaki, K.; Sato, Y.; Ohsaki, E.; Mori, Y.; Yamanishi, K.; Ueda, K. Novel monoclonal antibodies for identification of multicentric Castleman's disease; Kaposi's sarcoma-associated herpesvirus-encoded vMIP-I and vMIP-II. Virology 2012, 425, 95-102.

74. Scalley-Kim, M.L.; Hess, B.W.; Kelly, R.L.; Krostag, A.R.; Lustig, K.H.; Marken, J.S.; Ovendale, P.J.; Posey, A.R.; Smolak, P.J.; Taylor, J.D.; et al. A novel highly potent therapeutic antibody neutralizes multiple human chemokines and mimics viral immune modulation. PLoS One 2012, 7, e43332.

75. Compagno, M.; Lim, W.K.; Grunn, A.; Nandula, S.V.; Brahmachary, M.; Shen, Q.; Bertoni, F.; Ponzoni, M.; Scandurra, M.; Califano, A.; et al. Mutations of multiple genes cause deregulation of NF-kappaB in diffuse large B-cell lymphoma. Nature 2009, 459, 717-721.

76. Field, N.P.; Gal-Oz, E.; Bonanno, G.A. Continuing bonds and adjustment at 5 years after the death of a spouse. J. Consult. Clin. Psychol. 2003, 71, 110-117.

77. Liu, L.; Eby, M.T.; Rathore, N.; Sinha, S.K.; Kumar, A.; Chaudhary, P.M. The human herpes virus 8-encoded viral FLICE inhibitory protein physically associates with and persistently activates the Ikappa B kinase complex. J. Biol. Chem. 2002, 277, 13745-13751.

78. Field, N.; Low, W.; Daniels, M.; Howell, S.; Daviet, L.; Boshoff, C.; Collins, M. KSHV vFLIP binds to IKK-gamma to activate IKK. J. Cell Sci. 2003, 116, 3721-3728.

79. Keller, S.A.; Schattner, E.J.; Cesarman, E. Inhibition of NF-kappaB induces apoptosis of KSHV-infected primary effusion lymphoma cells. Blood 2000, 96, 2537-2542. 
80. Hussain, A.R.; Ahmed, S.O.; Ahmed, M.; Khan, O.S.; Al Abdulmohsen, S.; Platanias, L.C.; Al-Kuraya, K.S.; Uddin, S. Cross-talk between NFkB and the PI3-kinase/AKT pathway can be targeted in primary effusion lymphoma (PEL) cell lines for efficient apoptosis. PLoS One 2012, 7 , e39945.

81. Gopalakrishnan, R.; Matta, H.; Chaudhary, P.M. A purine scaffold HSP90 inhibitor BIIB021 has selective activity against KSHV-associated primary effusion lymphoma and blocks vFLIP K13-induced NF-kappaB. Clin. Cancer Res. 2013, 19, 5016-5026.

82. Nayar, U.; Lu, P.; Goldstein, R.L.; Vider, J.; Ballon, G.; Rodina, A.; Taldone, T.; Erdjument-Bromage, H.; Chomet, M.; Blasberg, R.; et al. Targeting the Hsp90-associated viral oncoproteome in gammaherpesvirus-associated malignancies. Blood 2013, 122, 2837-2847.

83. Pearl, L.H.; Prodromou, C. Structure and mechanism of the Hsp90 molecular chaperone machinery. Annu. Rev. Biochem. 2006, 75, 271-294.

84. Messaoudi, S.; Peyrat, J.F.; Brion, J.D.; Alami, M. Recent advances in Hsp90 inhibitors as antitumor agents. Anti-Cancer Agents Med. Chem. 2008, 8, 761-782.

85. Chen, W.; Sin, S.H.; Wen, K.W.; Damania, B.; Dittmer, D.P. Hsp90 inhibitors are efficacious against Kaposi Sarcoma by enhancing the degradation of the essential viral gene LANA, of the viral co-receptor EphA2 as well as other client proteins. PLoS Pathog. 2012, 8, e1003048.

86. Biamonte, M.A.; Van de Water, R.; Arndt, J.W.; Scannevin, R.H.; Perret, D.; Lee, W.C. Heat shock protein 90: Inhibitors in clinical trials. J. Med. Chem. 2010, 53, 3-17.

87. Goloudina, A.R.; Demidov, O.N.; Garrido, C. Inhibition of HSP70: A challenging anti-cancer strategy. Cancer Lett. 2012, 325, 117-124.

88. Lewis, J.; Devin, A.; Miller, A.; Lin, Y.; Rodriguez, Y.; Neckers, L.; Liu, Z.G. Disruption of hsp90 function results in degradation of the death domain kinase, receptor-interacting protein (RIP), and blockage of tumor necrosis factor-induced nuclear factor-kappaB activation. J. Biol. Chem. 2000, 275, 10519-10526.

89. Thangjam, G.S.; Dimitropoulou, C.; Joshi, A.D.; Barabutis, N.; Shaw, M.C.; Kovalenkov, Y.; Wallace, C.M.; Fulton, D.J.; Patel, V.; Catravas, J.D. Novel mechanism of attenuation of LPS-induced NF-kappaB activation by the heat shock protein 90 inhibitor, 17-N-allylamino-17-demethoxygeldanamycin, in human lung microvascular endothelial cells. Am. J. Respir. Cell Mol. Biol. 2014, 50, 942-952.

90. Gao, S.J.; Boshoff, C.; Jayachandra, S.; Weiss, R.A.; Chang, Y.; Moore, P.S. KSHV ORF K9 (vIRF) is an oncogene which inhibits the interferon signaling pathway. Oncogene 1997, 15, 1979-1985.

91. Rivas, C.; Thlick, A.E.; Parravicini, C.; Moore, P.S.; Chang, Y. Kaposi's sarcoma-associated herpesvirus LANA2 is a B-cell-specific latent viral protein that inhibits p53. J. Virol. 2001, 75, 429-438.

92. Chang, Y.; Moore, P.S.; Talbot, S.J.; Boshoff, C.H.; Zarkowska, T.; Godden, K.; Paterson, H.; Weiss, R.A.; Mittnacht, S. Cyclin encoded by KS herpesvirus. Nature 1996, 382, 410.

93. Verschuren, E.W.; Hodgson, J.G.; Gray, J.W.; Kogan, S.; Jones, N.; Evan, G.I. The role of p53 in suppression of KSHV cyclin-induced lymphomagenesis. Cancer Res. 2004, 64, 581-589. 
94. Sugaya, M.; Watanabe, T.; Yang, A.; Starost, M.F.; Kobayashi, H.; Atkins, A.M.; Borris, D.L.; Hanan, E.A.; Schimel, D.; Bryant, M.A.; et al. Lymphatic dysfunction in transgenic mice expressing KSHV k-cyclin under the control of the VEGFR-3 promoter. Blood 2005, 105, 2356-2363.

95. Freedman, D.A.; Wu, L.; Levine, A.J. Functions of the MDM2 oncoprotein. Cell. Mol. Life Sci. 1999, 55, 96-107.

96. Vassilev, L.T. Small-molecule antagonists of p53-MDM2 binding: Research tools and potential therapeutics. Cell Cycle 2004, 3, 419-421.

97. Sarek, G.; Kurki, S.; Enback, J.; Iotzova, G.; Haas, J.; Laakkonen, P.; Laiho, M.; Ojala, P.M. Reactivation of the p53 pathway as a treatment modality for KSHV-induced lymphomas. J. Clin. Investig. 2007, 117, 1019-1028.

98. Sarek, G.; Ojala, P.M. p53 reactivation kills KSHV lymphomas efficiently in vitro and in vivo: New hope for treating aggressive viral lymphomas. Cell Cycle 2007, 6, 2205-2209.

(C) 2014 by the authors; licensee MDPI, Basel, Switzerland. This article is an open access article distributed under the terms and conditions of the Creative Commons Attribution license (http://creativecommons.org/licenses/by/3.0/). 